\title{
MECHANISMS OF CONTRACTION AND RELAXATION IN HUMAN TERM PREGNANT MYOMETRIUM
}

\author{
Sadlonova V.,, Dokus K., ${ }^{2}$ Janicek F., ${ }^{1,2}$ Visnovsky J., ${ }^{2}$ Franova S. ${ }^{1}$
}

${ }^{1}$ Department of Pharmacology, Jessenius Faculty of Medicine, Comenius University, Martin ${ }^{2}$ Clinic of Obstetrics and Gynecology, Jessenius Faculty of Medicine and Martin University Hospital, Martin, Slovak Republic

\begin{abstract}
The study discusses the problem of role of various substances in the mechanisms of contraction and relaxation of human term pregnant myometrium in the experimental in vitro conditions.

Human myometrium tissue samples were collected from term pregnant women who had to undergo Caesarean section. The effects of potassium ion channels openers and closers, phosphodiesterase inhibitors and tachykinins were measured in the reactivity of human term pregnant myometrium in the experimental in vitro conditions.

Specific agonist-opener of $\mathrm{K}_{\text {ATP }}$ potassium ion channels - pinacidil significantly reduced contractile activity of human term pregnant myometrial strips induced by administration of oxytocin in in vitro conditions, while the effect of specific agonist-opener of $\mathrm{BK}_{\mathrm{Ca} 2+}$ potassium ion channels - NS1619 was not significant. Glibenclamide, specific $\mathrm{K}_{\mathrm{ATP}}$ potassium ion channels antagonist-closer significantly increased contractile activity of human term pregnant myometrial strips in in vitro conditions. The contractile effect of specific antagonist-closer of $\mathrm{BK}_{\mathrm{Ca} 2+} \mathrm{potassi}$ um ion channels - tetraethylammonium was not significant. Phosphodiesterase-4 inhibitor - rolipram and phosphodiesterase-5 inhibitor - sildenaphil led to statistically significant decrease of oxytocin-induced contractile activity in human term pregnant myometrial strips in in vitro conditions. Tachykinins - neurokinin A, neurokinin B and substance P markedly stimulated the activity of the human term pregnant myometrial strips in in vitro conditions.

The results showed the different effectiveness of potassium ion channels openers and closers, phosphodiesterase inhibitors as well as tachykinins in the mechanisms of contraction and relaxation of human term pregnant myometrium in in vitro conditions.
\end{abstract}

Key words: phosphodiesterase inhibitors, potassium ion channels openers and closers, tachykinins

\section{INTRODUCTION}

Myometrium is characterized by the presence of various receptors and ion channels that activity can be pharmacologically modulated. The majority of receptor-controlled physiological processes are regulated by ion channels. The role of ion channels in influencing uterine activity is important not only for contraction but relaxation, too. Potassium ion channels are the largest family of ion channels and are widely represented in smooth muscle including myometrium $(1,2,3)$ and are involved in mediating smooth muscle relaxation $(2$, 4 , 5). The ligand-sensitive potassium large conductance calcium-activated ion channel $\left(\mathrm{BK}_{\mathrm{Ca} 2}\right)$ is activated by membrane depolarization and also by an increase in the intracellular calcium concentration, thereby playing a pivotal role in the modulation of uterine contractility and myometrial calcium homeostasis (6). The opening of ATP-sensitive potassium ion channels $\left(\mathrm{K}_{\mathrm{ATP}}\right)$ results in an outward flow of $\mathrm{K}^{+}$ions, drawing the cell membrane potential closer to the $\mathrm{K}^{+}$equilibrium potential, and thereby reducing cellular excitability and contractility (6).

Phosphodiesterases (PDE) are the family of enzymes that catalyze the hydrolysis of 3 cyclic phosphate bonds cAMP and/or cGMP and based on their organ distribution they affect different functions. Each cell type can produce several different subtypes of PDE and myometrial cells are no exception. One of the mechanisms responsible for the relaxation of the

Address for correspondence:

Vladimira Sadlonova, MD, PhD, Department of Pharmacology, Jessenius Faculty of Medicine, Comenius University, Sklabinska 26, SK-036 01 Martin, Slovakia

Phone: +421 43 2633603, e-mail: vsadlonova@jfmed.uniba.sk 
myometrial smooth muscle is the elevation of cyclic adenosine monophosphate (cAMP) and partly cyclic guanosine monophosphate (cGMP) (7). To date, there is an interest in the substances known as the PDE inhibitors that can have an important role in the process of relaxation of myometrium $(7,8)$.

Tachykinin peptides are one of the largest family of neuropeptides whose biological effects are mediated via selective $\mathrm{NK}_{1}, \mathrm{NK}_{2}$ and $\mathrm{NK}_{3}$ neurokinin receptors, respectively for substance $\mathrm{P}(\mathrm{SP})$, neurokinin A (NKA) and neurokinin $\mathrm{B}(\mathrm{NKB})(9,10)$. All tachykinin receptors are members of the 7 -transmembrane-G-protein-coupled family receptors and induce the activation of phospholipase $\mathrm{C}$, producing inositol triphosphate $(11,12)$. Distribution and agonist-mediated uterotonic effect of all three neurokinin receptors in human uterus has been reported $(13,14,15)$.

The aim of the study was to assess mechanisms of contraction and relaxation of human term pregnant myometrium in the experimental in vitro conditions using potassium ion channels openers (pinacidil and NS1619) and potassium ion channels closers (glibenclamide and tetraethylammonium), phosphodiesterase inhibitors (rolipram and sildenaphil) as well as tachykinins (neurokinin A, neurokinin B and substance P).

\section{METHODS}

Human myometrium tissue samples were collected from term pregnant women who had to undergo Caesarean section. The sample of myometrium tissue was excised at the Clinic of Obstetrics and Gynecology of Jessenius Medical Faculty, using a scalpel, from the uterine incision made at Caesarean section in the lower uterine segment and placed in KrebsHenseleit buffer. This buffer containig $(\mu \mathrm{M})$ : $\mathrm{NaCl}, 110.0 ; \mathrm{KCl}, 4.8 ; \mathrm{CaCl}_{2}, 2.35 ; \mathrm{MgSO}_{4}$, 1.20; $\mathrm{KHPO}_{4}, 1.20 ; \mathrm{NaHCO}_{3}, 25.0$; in distilled water, maintains the survival of the sample. After the excision, the sample from each woman was immediately processed into myometrial strip of approximate size of $7 \times 2 \mathrm{~mm}$ at the Department of Pharmacology of Jessenius Medical Faculty. The time from sample excision to make the strip was only a few minutes.

Then human myometrial strips were given into an organ bath with Krebs-Henseleit buffer. Organ chambers were maintained at $36.5 \pm 0.5^{\circ} \mathrm{C}$ and were aerated continuously with the mixture $95 \% \mathrm{O}_{2}$ and $5 \% \mathrm{CO}_{2}$, to maintain $\mathrm{pH}=7.5 \pm 0.1$.

The contractile activity of human term pregnant myometrial strips were induced by the oxytocin administration into organ bath. The mean peak amplitude of contraction of the myometrial strips to the doses of oxytocin with subsequent administration of potassium ion channels openers (pinacidil and NS1619), potassium ion channels closers (glibenclamide and tetraethylammonium), phosphodiesterase inhibitors (rolipram and sildenaphil) and tachykinins (neurokinin A, neurokinin B and substance P) were measured as a parameter of human term pregnant myometrial reactivity in in vitro conditions.

Contractile activity was measured isometrically using force tranducer (TSR 10G, Vývoj Martin, Slovakia), amplifier (M 1101 SUPR, Mikrotechna Praha, Czech Republic). Oxytocin

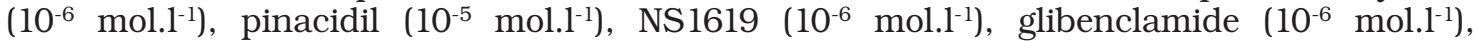
tetraethylammonium $\left(10^{-4}\right.$ mol.1 $\left.1^{-1}\right)$, rolipram $\left(10^{-4}\right.$ mol. $\left.1^{-1}\right)$, sildenaphil $\left(10^{-4} \mathrm{~mol}^{-1}\right)$, neurokinin A $\left(10^{-6}\right.$ mol. $\left.\mathrm{l}^{-1}\right)$, neurokinin B $\left(10^{-6}\right.$ mol. $\left.\mathrm{l}^{-1}\right)$ and substance $\mathrm{P}\left(10^{-6} \mathrm{~mol} . \mathrm{l}^{-1}\right)$ were purchased from Sigma Chemicals Co, Germany.

Patient recruitment was carried out by provision of information sheets and by obtaining written informed consent. All procedures were carried out according to EU directives and reviewed by Ethical Committee of the Comenius University.

Statistical analysis was performed using $t$-test and one-way variance analysis (ANOVA). 


\section{RESULTS}

Specific agonist-opener of $\mathrm{K}_{\text {ATP }}$ potassium ion channels - pinacidil significantly reduced contractile activity $(\mathrm{p}<0.05)$ of human term pregnant myometrial strips induced by administration of oxytocin in in vitro conditions (Fig. 1A). Pinacidil showed the decrease in contractile amplitude of oxytocin-induced contraction to $30.23 \%$. This tocolytic effect of pinacidil was confirmed by the application of its specific antagonist-closer of $\mathrm{K}_{\text {ATP }}$ potassium ion channels - glibenclamide that significantly increased the contractile activity $(\mathrm{p}<0.05)$ of human term pregnant myometrial strips by $72 \%$ in in vitro conditions (Fig. 1A). In contrast, specific agonist-opener of $\mathrm{BK}_{\mathrm{Ca} 2+}$ potassium ion channels - NS1619 decreased contractile activity in human term pregnant myometrial strips induced by oxytocin in in vitro conditions, but not significantly (Fig. 1B). NS1619 showed the decrease in contractile amplitude of oxytocin-induced contraction to $76.8 \%$. Similarly, its specific antagonist-closer of $\mathrm{BK}_{\mathrm{Ca} 2+}$ potassium ion channels - tetraethylammonium increased the contractile activity of human term pregnant myometrial strips by $29.2 \%$ in in vitro conditions, but its effect was not significant (Fig. 1B).

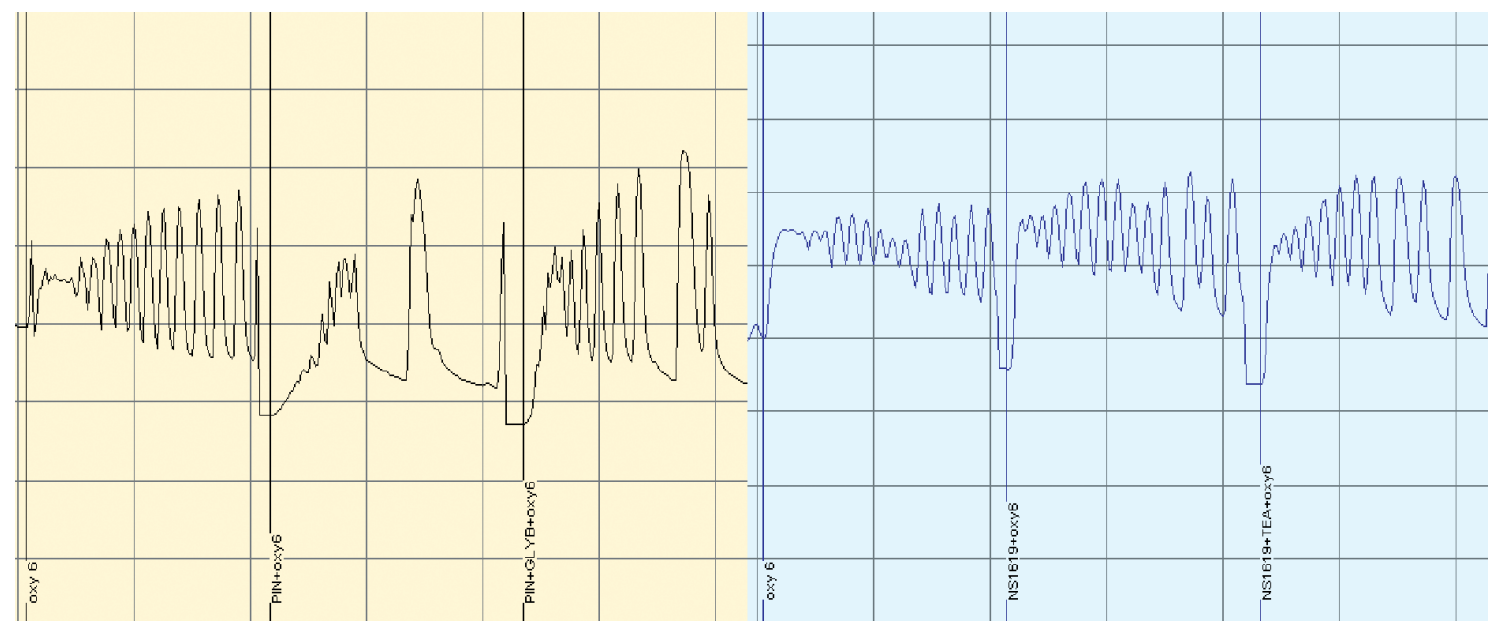

Fig. 1.

A: The record of the reactivity of human term pregnant myometrial strips after administration of specific $\mathrm{K}_{\mathrm{ATP}}$ opener pinacidil and specific $\mathrm{K}_{\mathrm{ATP}}$ closer glibenclamide in the experimental in vitro conditions (21).

$\mathrm{B}$ : The record of the reactivity of human term pregnant myometrial strips after the administration of specific $\mathrm{BK}_{\mathrm{Ca} 2+}$ opener NS1619 and specific $\mathrm{BK}_{\mathrm{Ca}_{2}+}$ closer tetraethylammonium in the experimental in vitro conditions (21).

1 segment on the $\mathrm{x}$-axis represents 5 minutes and on $\mathrm{y}$-axis $0.5 \mathrm{mN}$.

Phosphodiesterase-4 inhibitor - rolipram and phosphodiesterase- 5 inhibitor - sildenaphil led to statistically significant decrease of oxytocin- induced contractile activity $(p<0.05)$ in human term pregnant myometrial strips in in vitro conditions (Fig. 2A, 2B). Therapy with rolipram showed the decrease in contractile amplitude of oxytocin-induced contraction to $47.98 \%$ and with sildenaphil to $37.9 \%$. 


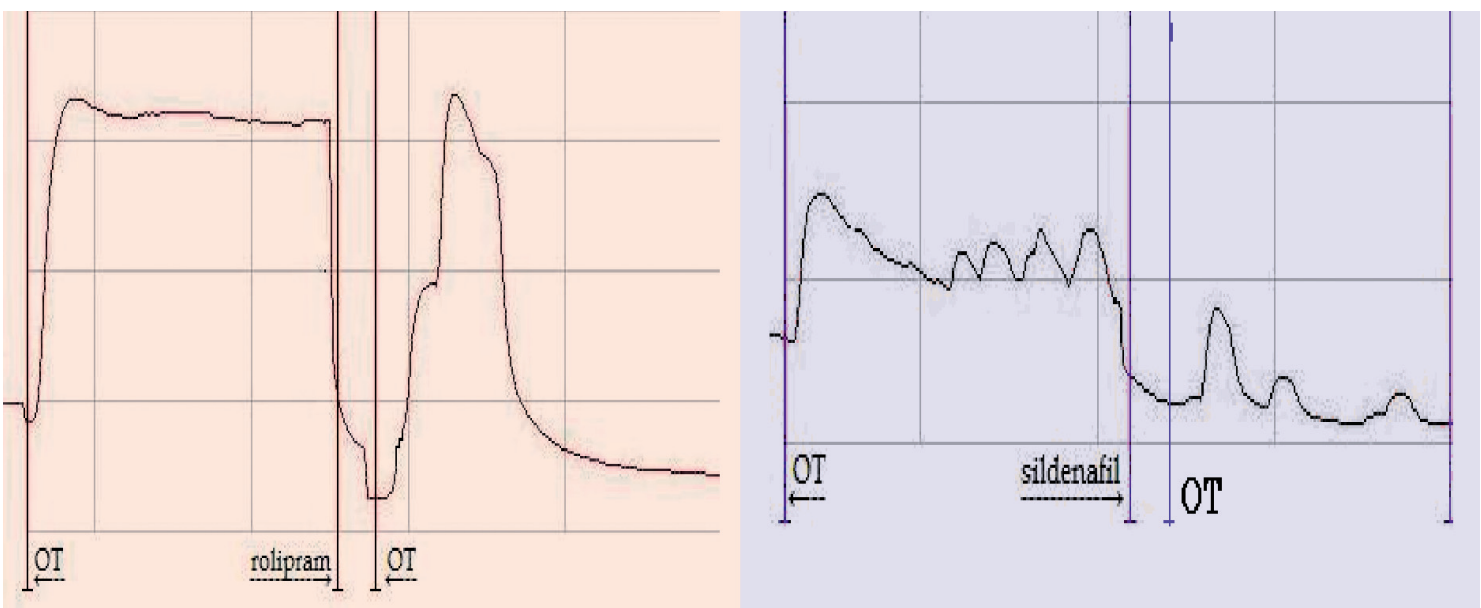

Fig. 2.

A: The record of the reactivity of human term pregnant myometrial strips after the administration of PDE4 rolipram in the experimental in vitro conditions (23).

B: The record of the reactivity of human term pregnant myometrial strips after the administration of PDE5 sildenaphil in the experimental in vitro conditions (23).

1 segment on the $\mathrm{x}$-axis represents 5 minutes and on $\mathrm{y}$-axis $0.5 \mathrm{mN}$

Tachykinins - neurokinin A, neurokinin B and substance P markedly stimulated the activity of the human term pregnant myometrial strips (Fig, 3A, 3B, 4A). In neurokinin A the change of amplitude exceeded the spontaneous activity of the term pregnant myometrial strips by $43.1 \%$, in neurokinin B by $38.1 \%$ and in substance P by $39.7 \%$. The contractile activity of oxytocin was $36.1 \%$. Tachykinins in in vitro conditions had a very similar effect on myometrial contractility which can be compared to stimulating effect, in practice approved and used oxytocin. (Fig. 4B).
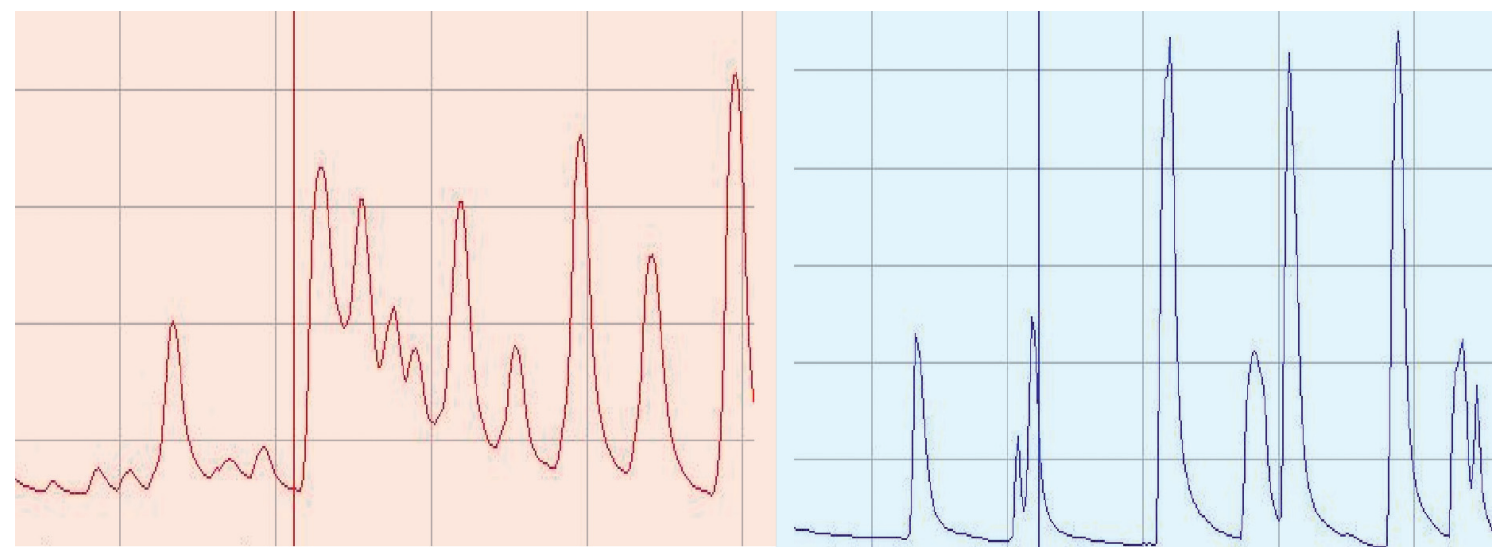

Fig. 3.

A: The record of the reactivity of human term pregnant myometrial strips in the experimental in vitro conditions after the administration of neurokinin A.

$\mathrm{B}$ : The record of reactivity of human term pregnant myometrial strips in the experimental in vitro conditions after the administration of neurokinin $B$.

1 segment on the $\mathrm{x}$-axis represents 5 minutes and on $\mathrm{y}$-axis $0.5 \mathrm{mN}$. 

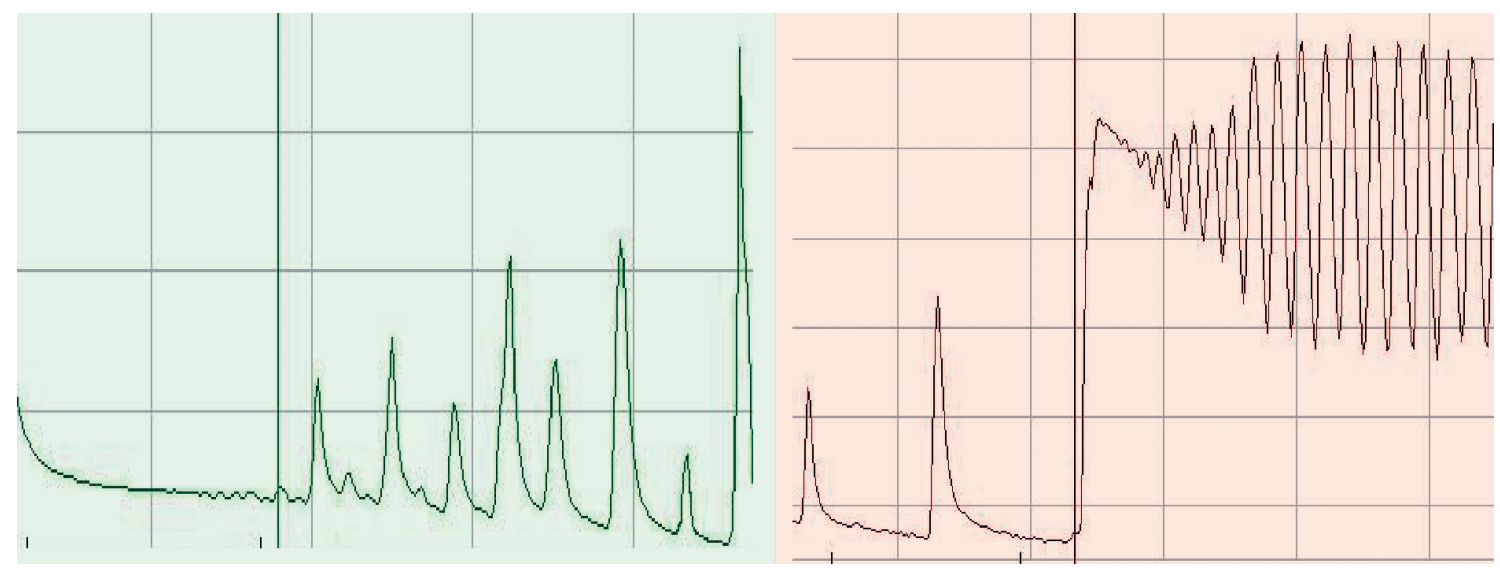

Fig. 4.

A: The record of reactivity of human term pregnant myometrial strips in the experimental in vitro conditions after the administration of substance $P$.

B: The record of reactivity of human term pregnant myometrial strips in the experimental in vitro conditions after the administration of oxytocin.

1 segment on the $\mathrm{x}$-axis represents 5 minutes and on $\mathrm{y}$-axis $0.5 \mathrm{mN}$.

\section{DISCUSSION}

The results of our experimental study showed the different effectiveness of potassium ion channels openers and potassium ion channels closers, phosphodiesterase inhibitors as well as tachykinins in mechanisms of contraction and relaxation of human term pregnant myometrium in in vitro conditions.

The effects of $\mathrm{BK}_{\mathrm{Ca2}+}$ and $\mathrm{K}_{\mathrm{ATP}}$ potassium ion channels in myometrium are probably dependent on many various factors or conditions. There are differences between experimental studies in animals $(16,17,18)$ and clinical studies in humans $(19,20)$. In human myometrium the presence of these channels depend on functional state of myometrium that means non pregnant, mid pregnant, term pregnant not in labour, term pregnant in labour or late pregnant myometrium. In our experiment all samples of the human myometrium tissue were obtained from term pregnant women. We have found that the activity of $\mathrm{K}_{\text {ATP }}$ potassium ion channels in human term pregnant myometrial strips was high, which resulted in a significant decrease of contractile activity of myometrial strips in in vitro conditions. In contrast, the activity of $\mathrm{BK}_{\mathrm{Ca} 2+}$ potassium ion channels in the contractility of human term pregnant myometrial strips was reduced and did not lead to significant decrease of contractile activity of myometrial strips in in vitro conditions. The results of our experiment showed a different participation of $\mathrm{BK}_{\mathrm{Ca} 2+}$ and $\mathrm{K}_{\mathrm{ATP}}$ potassium ion channels in the contractility of human term pregnant myometrium in in vitro conditions (21). $\mathrm{BK}_{\mathrm{Ca} 2+}$ potassium ion channels probably have a more important function to induce contractions of human term pregnant myometrium in labour.

Phosphodiesterase-4 inhibitor - rolipram and phosphodiesterase- 5 inhibitor - sildenaphil led to statistically significant decrease of oxytocin-induced contractile activity in human term pregnant myometrial strips in in vitro conditions. The tocolytic effects of inhibitors of phosphodiesterases were the result of the increase of intracellular cyclic nucleotides, in the case of rolipram cAMP and cGMP in sildenaphil. Some experimental studies show that PDE inhibitors could represent a possible future therapeutic potential in the process of myometrial contractility modulation $(8,22,23)$.

It is known that tachykinins stimulate activity of phospholipase C via G-protein that connects mainly to $\mathrm{Ca}^{2+}$ influx through VOCs (voltage-operated channels) channels (24), in the 
same manner as oxytocin causes the stimulatory respond by binding to its receptor (25). In our study, all three tachykinins had shown to be more potent stimulators of contractility of human term pregnant myometrial strips than oxytocin which also indicates their probable role in the initiation of parturition. In conclusion, the results indicate that tachykinins produce their stimulatory effects probably via mutual nonspecific co-operation of tachikinins receptors $\mathrm{NK}_{1}, \mathrm{NK}_{2}$ and $\mathrm{NK}_{3}$.

The mechanisms that influence the membrane potential and excitability of myometrial smooth muscle cell are not still clear. There are many experimental studies that discuss this issue in order to find "ideal" substance that could be effective in the management of labour and does not have a negative impact on the organism both mother and fetus.

We discuss the effects of various substances that participate in the mechanisms of contraction and relaxation in human term pregnant myometrium in in vitro conditions. This experimental study is only the beginning of our research. In the next experiments we would like to use other substances eventually combination of substances and discuss this problem more detailed.

\section{REFERENCES}

1. Khan RN, Smith SK, Morrison JJ, Ashford ML. Properties of largeconductance K+ channels in human myometrium during pregnancy and labour. Proc Biol Sci 1993; 251: 9-15.

2. Anwer K, Oberti C, Perez GJ, Perez-Reyes N, McDougall JK, Monga M, Sanborn BM, Stefani E, Toro L. Calciumactivated $\mathrm{K}+$ channels as modulators of human myometrialcontractile activity. Am J Physiol 1993; 265: 976985.

3. Chanrachakul B, Matharoo-Ball B, Turner A, Robinson G, Broughton-Pipkin F, Arulkumaran S, Khan RN. Immunolocalization and protein expression of the alpha subunit of the large-conductance calcium-activated potassium channel in human myometrium. Reproduction 2003; 126: 43-48.

4. Khan RN, Smith SK, Ashford ML. Contribution of calcium-sensitive potassium channels to NS1619- induced relaxation in human pregnant myometrium. Hum Reprod 1998; 13: 208-213.

5. Chanrachakul B, Broughton-Pipkin F, Khan RN. The large conductance calcium-activated potassium channel (BKCa) and the beta 2 adrenergic receptor (AR): a direct link to uterine relaxation. Physiol News 2004; 55: 2223.

6. Khan RN, Matharoo-Ball B, Arulkumaran S, Ashford MLJ. Potassium channels in the human myometrium. Exp Physiol 2001; 86: 255-264.

7. Riemer RK, Heymann MA. Regulation of uterine smooth muscle function during gestation. Pediatr Res 1998; 44: 615-627.

8. Oger S, Mehats C, Barnette M, Ferre F, Cabrol D, Leroy MJ. Anti-inflamatory and uterorelaxant effect in human myometrium of new generation phosphodiesterase 4 inhibitors. Biol Reprod 2004; 70: 458-464.

9. Guard S, Watson SP. Tachykinin receptor types: classification and transmembrane signaling mechanisms. Neurochem Int 1991; 18: 149-166.

10. Stratowa C, Machat H, Burger E, Himmler A, Schafer R, Spevak W, Weyer U, Wiche-Castanon M, Czernilofsky AP. Functional characterization of the human neurokinin receptors NK1, NK2 and NK3 based on a cellular assay system. J Recept Signal Transduct Res 1995; 15: 617-630.

11. Gerard NP, Bao L, Xiao-Ping H, Gerard C. Molecular aspects of the tachykinin receptors. Regul Pept 1993; 43: 21-35.

12. Krause JE, Blount P, Sachais BS. Molecular biology of receptors. Structures, expression and regulatory mechanisms. In: Buck SH (ed) The tachykinin receptors. Tolowa: Humana Press; 1994. p.165-218.

13. Barr AJ, Watson SP, Lopez Bernal A, Nimmo AJ. The presence of NK3 tachykinin receptors on rat uterus. Eur J Pharmacol 1991; 203: 287-290.

14. Pennefather JN, Zeng XP, Gould D, Hall S, Burcher E. Mammalian tachykinins stimulate rat uterus by activating NK2 receptors. Peptides 1993; 14: 169-174.

15. Patak E, Pennefathet JN, Fleming A, Story ME. Functional characterization of tachykinin NK1 receptors in the mouse uterus. Brit J Pharmacol 2002; 137: 1247-1254.

16. Mandi G, Sarkar SN, Mishra SK, Raviprakash V. Effects of calcium channel blocker, mibefradil, and potassium channel opener, pinacidil, on the contractile response of mid-pregnant goat myometrium. Indian J Exp Biol 2005; 43: 795-801.

17. Novakovic R, Milovanovic S, Protic D, Djokic J, Heinle H, Gojkovic-Bukarica L. The effect of potassium channel opener pinacidil on the non-pregnant rat uterus. Basic Clin Pharmacol Toxicol 2007; 101: $181-186$.

18. Franova S, Janicek F, Nosalova G, Sutovska M, Visnovsky J. In vitro contractile response of rabbit myometrium to $\mathrm{BK}_{\mathrm{Ca}}$ and $\mathrm{K}_{\mathrm{ATP}}$ potassium channel openers. Acta Vet Brno 2009; 78: 13-18. 
19. Brainard AM, Korovkina VP, England SK. Potassium channels and uterine function. Semin Cell Dev Biol 2007; 18: 332-339.

20. Gao L, Cong B, Zhang L, Ni X. Expression of the calcium-activated potassium channel in upper and lower segment human myometrium during pregnancy and parturition. Reprod Biol Endocrinol 2009; 7: 27.

21. Sadlonova V, Franova S, Dokus K, Janicek F, Visnovsky J, Sadlonova J. Participation of $\mathrm{BK}_{\mathrm{Ca} 2^{+}}$and $\mathrm{K}_{\mathrm{ATP}}$ potassium ion channels in the contractility of human term pregnant myometrium in in vitro conditions. $J$ Obstet Gynaecol Res 2011; 37: 215-221.

22. Leroy MJ, Cedrin I, Breuiller M, Giovagrandi Y, Ferre F. Correlation between selective inhibition of the cyclic nucleotide phosphodiesterases and the contractile activity in human pregnant myometrium near term. Biochem Pharmacol 1989; 38: 9-15.

23. Franova S, Janicek F, Visnovsky J, Dokus K, Zubor P, Sutovska M, Nosalova G. Utero-relaxant effect of PDE4selective inhibitor alone and in simultaneous administration with 2-mimetic on oxytocin-induced contrations in pregnant myometrium. J Obstet Gynaecol Res 2009; 35: 20-25.

24. Magraner J, Morcillo E, Ausina P, Pinto FM, Martin JD, Moreau J, Anselmi E, Barrachina MD, Cortijo J, Advenier C, Candenas ML. Effects of Mn 2+ on the responses induced by different spasmogens in the oestrogen-primed rat uterus. Eur J pharmacol 1997; 326: 211-222.

25. Wray S. Uterine contraction and physiological mechanisms of modulation. AM J Physiol 1993; 264: 1-18.

Received: Oct, 26, 2011

Accepted: Dec, 7, 2011 